\title{
Clinical Findings Among Nigerian Paediatric Glaucoma Suspects During A School Eye Health Survey
}

\author{
Abdulkabir Ayansiji Ayanniyi ${ }^{*},{ }^{,}$, Fatai Olasunkanmi Olatunji ${ }^{1}$, \\ Abdulraheem Olarongbe Mahmoud ${ }^{1}$ and Rashidat Oluwafunke Ayanniyi ${ }^{2}$ \\ ${ }^{I}$ Department of Ophthalmology, University of Ilorin Teaching Hospital, Ilorin, Nigeria \\ ${ }^{2}$ Department of Pharmacology and Therapeutics, University of Ilorin, Nigeria
}

\begin{abstract}
Objective: To report clinical findings suspicious of glaucoma among primary school children in Ilorin, Nigeria.
Methods: A cross sectional survey of ocular health among 1,393 school children carried out between July 2005 and January 2006. Criteria for suspecting glaucoma included a cup disc ratio (CD) of $>0.5$, a CD asymmetry between the fellow eyes of $>0.2$, and/or intraocular pressure (IOP) $>21 \mathrm{mmHg}$ by applanation tonometry.

Results: Eleven ( 6 boys and 5 girls) of 1,393 pupils (0.8\%), aged between 7 and 13 years, had ocular findings suspicious of glaucoma. Twenty two eyes of 11 pupils had a CD ratio $\geq 0.6$, and among these 5 eyes had IOP $>21$. Three of the pupils had a CD asymmetry of $>0.2$.

Conclusion: A significant proportion of these Nigerian school pupils had clinical signs suggestive of glaucoma. A functional school health programme with eye health component coupled with efficient referral system is advocated.
\end{abstract}

Keywords: School eye screening, glaucoma suspect, referral system.

\section{INTRODUCTION}

Glaucoma is a dreaded blinding eye disease yet vision can be preserved if detected early and necessary intervention employed. Glaucoma has characteristic features that give away its diagnosis such as progressive visual field loss and optic nerve head damage among others $[1,2]$. However, the presence of these characteristic features implies certain degree of visual loss. The prospect of preserving lifetime useful vision in glaucomatous eyes lies in early diagnosis and intervention.

At its very early stage the diagnosis of glaucoma is not only difficult but also requires sophisticated resources [2,3]. This is a challenge for screening for glaucoma more especially in resource limited economy. The limitation notwithstanding, there are ocular clinical features that can arouse suspicion of glaucoma once they are found during eye examination. Although these clinical features alone may not necessarily confirm glaucoma, they would be found useful in situations where sophisticated resources are not available more especially where rapid screening is required. This implies that individuals with eyes examination findings suspicious of glaucoma would be referred appropriately for further ophthalmic evaluation at ophthalmic clinic.

Usually the diagnosis of glaucoma heralds fear, anxiety and hopelessness when first detected at an advanced stage. However, studies have shown that detection of glaucoma at an early stage and institution of appropriate intervention can ensure preservation of a lifetime useful visual function $[4,5]$.

*Address correspondence to this author at the Department of Ophthalmology, University of Ilorin Teaching Hospital, Ilorin, Nigeria; Tel: +2348058548765; E-mail: ayanniyikabir@yahoo.com
Many ocular problems that are amenable to interventional measures (including glaucoma) are detected through vision screening of selected population such as school children [68]. Eye surveys have potential to promote normal vision, preserve healthy eyes and prevent blindness [9]. The aim of this paper is to report clinical findings suspicious of glaucoma among primary school children in Ilorin, Nigeria, with the view that such features can serve as basis for referral especially during epidemiological eye surveys to ophthalmic clinics where further evaluation to confirm or rule out glaucoma can be done.

\section{MATERIALS AND METHODS}

This study formed part of a large ocular health survey among school children in Ilorin, Nigeria. It was a crosssectional descriptive study carried out between July 2005 and January 2006 in 10 randomly selected non-residential primary schools within Ilorin, an urban city in Nigeria. One thousand three hundred and ninety three sampled pupils from the selected schools were surveyed. The population of school children in Ilorin metropolis was approximately 166,000 as at July 2005.

Ethical clearance for the study was obtained from University of Ilorin Teaching Hospital. There were initial advocacy visits to the local school board and the selected schools to convey the objectives and importance of the study with a view to gaining support and permission to carry out the study.

The sample size of surveyed pupils was determined using the equation: $n=z^{2} p q / d^{2}$. Where $n$ is the desired sample size, $\mathrm{z}$ is the standard normal deviate $(\mathrm{z}$ is taken as 1.96 which corresponds to the $95 \%$ confidence level), $\mathrm{p}$ is the proportion 
(prevalence) of the children population estimated to have visual problem and $d$ is the degree of accuracy. The prevalence (p) of ocular pathology among school children from previous studies in Nigeria $[10,11,12]$ was $17 \%$. Thus $\mathrm{p}=$ $0.17, q=1.0-p=0.83$ and $d$ was set at $2 \%$ (i.e. 0.02 ). Thus the calculated minimal sample size (n) was 1355 . However, the study was carried out on 1393 pupils.

Multistage random sampling technique was employed to select the pupils. Generated random numbers were used to select 10 primary schools from a list of 184 primary schools within Ilorin metropolis. Each studied primary school had 6 classes and each class was subdivided into a number of arms. Using the calculated minimal sample size as well as the number of pupils in each class as a guide, a predetermined number of 30 pupils was randomly selected for the study from each class. Through the assistance of class teachers, all available pupils in all the arms of a particular class were assembled and each pupil was asked to pick a numbered wrapped paper. The pupils who picked the first 30 numbers were selected from each class for the study and thus a total number of 180 pupils from each school and an overall 1800 from 10 schools. The exclusion criteria included age 16 year and above, lack of guardian consent for pupil to participate, inability to cooperate with the examination process, failure of a child's guardian to complete relevant sections of the proforma, and earlier participation in the preceding pilot study.

The examinations were carried out in the classrooms in broad daylight. The presence of the class teachers ensured the co-operation of most pupils with the examination process. Visual acuity (VA) determination and a pin hole test was done for pupils with VA of $6 / 9$ or worse. With the aid of the pen torch the eyelids, the conjunctiva, the cornea, the anterior chamber, the iris and the pupil of each eye were examined. Other tests including colour vision test, Hirschberg test and cover-uncover test among others were also carried out. Reports of these are subject of another paper under consideration for publication elsewhere. With the aid of direct ophthalmoscope the posterior segment of the eyes of each pupil was examined in a darkened corner of the classroom (achieved by closing few windows). The eye was dilated with $0.5 \%$ tropicamide drops whenever mydriasis was required for fundoscopy.

The intra ocular pressure (IOP) of pupils whose ocular findings were suspicious of glaucoma was measured with a Perkins applanation tonometer. The criteria for suspecting glaucoma as used in the study included a cup disc ratio (CD) of $>0.5$, a CD asymmetry between the fellow eyes of $>0.2$, and/or intraocular pressure (IOP) $>21 \mathrm{mmHg}$ by applanation tonometry. Confrontation visual field test was carried out to detect gross visual field defects. Standard perimetry to detect visual field defects could not be carried out at the schools.

The pupils were referred to the University of Ilorin Teaching Hospital, for further review/ management/ follow up as appropriate. Post survey advocacy visits to sampled schools were carried out to meet the guardians of affected pupils in order to encourage them to follow their wards to referral hospital for further review/ management and to express appreciation to the school communities.

Data entry and analysis were done with Statistical Package for Social Scientist (SPSS) version 12.0.1.

\section{RESULTS}

One thousand three hundred and ninety three sampled pupils from 10 sampled schools including 689 (49.4\%) boys and $704(50.6 \%)$ girls ( $\mathrm{M}: \mathrm{F}=1: 1)$ were examined. The age range was between 4 and 15 years. The mean and modal ages were $10.16 \pm 2.5$ and 10 respectively. Eleven ( 6 boys and 5 girls) out of 1,393 pupils $(0.8 \%)$, aged between 7 and 13 years, had ocular findings suspicious of glaucoma (Table 1).

Six of the 22 eyes ( 3 pupils) had clinical findings such as pale disc with cup to disc ratio (CD) ranging between 0.60.9 , nasalised vessels, intraocular pressure (IOP) of $19 \mathrm{mmHg}$ in an eye and between 22 and $30 \mathrm{mmHg}$ in 5 eyes. The visual acuity (VA) was 6/6 in 5 eyes and Perception of Light (PL) in an eye. The pupils included 2 boys and a girl whose ages were 7,8 and 13 years (Table $\mathbf{1}$ ).

Table 1. Demographic Characteristics and Ocular Findings Among 11 Pupils

\begin{tabular}{|c|c|c|c|c|c|c|c|c|c|}
\hline S/N & Age & Sex & IOP RE & IOP RE & CD RE & CD RE & VARE & VALE & Other Findings \\
\hline \hline 1 & 7 & M & 22 & 19 & 0.9 & 0.6 & $6 / 6$ & $6 / 6$ & Nasalised vessels, pale discs \\
\hline 2 & 8 & F & 30 & 25 & 0.9 & 0.6 & PL & $6 / 6$ & Nasalised vessels, pale discs \\
\hline 3 & 13 & M & 22 & 24 & 0.6 & 0.9 & $6 / 6$ & $6 / 6$ & Nasalised vessels, pale discs \\
\hline 4 & 10 & F & 12 & 12 & 0.6 & 0.6 & $6 / 5$ & $6 / 5$ & \\
\hline 5 & 8 & M & 12 & 11 & 0.7 & 0.6 & $6 / 6$ & $6 / 6$ & \\
\hline 6 & 13 & F & 11 & 12 & 0.6 & 0.6 & $6 / 6$ & $6 / 6$ & \\
\hline 7 & 9 & M & 14 & 13 & 0.6 & 0.6 & $6 / 6$ & $6 / 6$ & Nasalised vessels \\
\hline 8 & 9 & F & 14 & 16 & 0.6 & 0.7 & $6 / 9$ & $6 / 9$ & \\
\hline 9 & 11 & M & 12 & 13 & 0.6 & 0.7 & $6 / 5$ & $6 / 6$ & $6 / 6$ \\
\hline 10 & 12 & M & 11 & 11 & 0.6 & 0.6 & $6 / 6$ & $6 / 6$ & \\
\hline 11 & 13 & F & 12 & 13 & 0.6 & 0.6 & $6 / 6$ & $6 / 6$ \\
\hline
\end{tabular}

IOPRE=intraocular pressure in the right eye, IOPLE=intraocular pressure in the left eye, CDRE=cup to disc ratio in the right eye, CDLE=cup to disc ratio in the left eye, VARE=visual acuity in the right eye, VALE=visual acuity in the left eye, $\mathrm{M}=$ male, $\mathrm{F}=\mathrm{female}, \mathrm{PL}=$ perception of light. 
The findings among remaining 16 eyes (8 pupils) included: CD of 0.6 in 13 eyes (with nasalised vessels in 2 of the eyes), and 0.7 in 3 eyes. The VA of the 16 eyes included $6 / 5$ in 3 eyes, 6/6 in 11 eyes and 6/9 in 2 eyes. All the 16 eyes had IOP ranging between 11 and $16 \mathrm{mmHg}$.

Although there was no history suggestive of glaucoma among the pupils' first-degree relatives, all the pupils were Blacks.

\section{DISCUSSION}

The finding of a prevalence of $0.8 \%$ for pupils with clinical features suspicious of glaucoma is significant. The cup to disc (CD) ratio of $>0.5$ as used in the study as a clinical feature suspicious of glaucoma was borne out of the fact that established glaucoma is usually associated with high CD ratio $[1,2,3]$. Diagnosis might further be strengthened if the subject had any or combination of positive family history of glaucoma, raised intraocular pressure and disc pallor [3]. A relatively high $\mathrm{CD}$ ratio may also be found among nonglaucomatous conditions such as myopes, some familiar cases, and generally among members of the Black race when compared to their Caucasian counterparts [3]. Though all the members of our cohort were Blacks, a history of glaucoma among the pupils' first degree relations could not be elicited. It is conceivable that poor health infrastructure and lack of awareness of glaucoma might have rendered the pupils' relations unaware of glaucoma among those who might have the disease.

Another clinical feature that heightened suspicion of glaucoma among the pupils was the presence of cup disc asymmetry in 3 pupils. The cup disc asymmetry in the presence of other risk factors for glaucoma heightens suspicion of glaucoma and such pupils need further evaluation. Nasalised vessels were also an important feature found among the cohort that could suggest glaucoma.

High IOP is a strong risk factor for glaucoma. Individuals with persistent raised IOP even in the absence of visual field and optic nerve defects are regarded as glaucoma suspects as they often show glaucomatous features over time [1,3,13]. Three of the pupils had IOP between 19 and $30 \mathrm{mmHg}$, pale disc, high $\mathrm{CD}$ ratio $\geq 0.6$ and one eye was already blind (VA of PL) from glaucoma. Though in the cohort, most had IOP in the acceptable normal range, glaucoma could not be totally ruled out in them in view of other findings suspicious of glaucoma. Studies have shown that IOP rises with age. Apart from this fact, IOP that is within statistical normal limits may be too high for an individual eye as found in nor$\mathrm{mal} /$ low tension glaucoma $[3,14,15,16]$.

We acknowledged that our method used in the case detection of the glaucoma suspects had its limitations. The use of measurement of intraocular pressure alone has been shown to be a poor predictor of glaucoma [17]. However, the combination of tonometry and fundoscopy that we used in our study had been shown to increase the sensitivity and specificity further to $61 \%$ and $84 \%$ respectively [18].

All eyes except one member of the cohort have normal visual acuity (VA). VA is not a good criterion for diagnosing glaucoma as it may be normal in advanced glaucoma [3].
Glaucoma is better diagnosed very early in order to preserve sight; hence the need for regular eye examination in the cohort of pupils before the signs become so obvious and the damage irreversible [19]. Controlling blindness from glaucoma requires early detection, life-long treatment and compliance of the patients [20]. The guardians of the cohort of pupils with ocular features of glaucoma were informed of the findings and they were appropriately referred for further review/follow up in the ophthalmic clinic.

Concluding, a significant proportion of pupils during a routine school eye health survey had clinical signs suggestive of glaucoma. A functional school health programme with eye health component coupled with efficient referral system is advocated.

\section{ACKNOWLEDGEMENT}

Our special appreciation goes to the local School Authority (Kwara State Universal Basic Education Board), the sampled schools, the guardians and cohort of pupils who were subjects of the study.

\section{REFERENCES}

[1] Bourne RRA. Glossary: The optic nerve head in glaucoma. Community Eye Health J 2006; 19: 44- 45.

[2] Thomas R, Parikh RS. How to assess a patient for glaucoma. Community Eye Health J 2006; 19: 36-37.

[3] Kanski JJ. Clinical Ophthalmology. Glaucoma: Optic nerve head. $6^{\text {th }}$ edition. China: Elsevier Butterworth-Heinemann 2007; 371-440.

[4] Wormald R. What is new in glaucoma treatment? Community Eye Health J 2006; 19: 33-35.

[5] Maier PC, Funk J, Schwarzer G, Antes G, Falck-Ytter YT. Treatment of ocular hypertension and open-angle glaucoma: metaanalysis of randomized controlled trials. BMJ 2005; 331 (7509): 134-137.

[6] Faderin MA, Ajaiyeoba AI. Refractive errors in primary school children in Nigeria. Nig J Ophthalmol 2001; 9: 10-14.

[7] Wedner S, Dineen B. Refractive errors. Trop Doc 2003; 33: 207 209.

[8] Abubakar S, Ajaiyeoba AI. Screening for eye disease in Nigeria school children. Nig J Ophthalmol 2001; 9: 6-9.

[9] Johnson GJ, Foster A. Prevalence, incidence and distribution of visual impairment. Epidemiology of eye disease. In: Johnson GJ, Minassian DC, Weale RA, West SK. Eds. $2^{\text {nd }}$ ed. London: Arnold publishers 2003; 3-28.

[10] Isawumi MA. Ocular disorders among school children in Osun State, Nigeria. Dissertation for the award of Fellowship Diploma of the National Postgraduate Medical College of Nigeria in Ophthalmology, 2003.

[11] Ugochukwu CIO. Survey of eye health status of primary school children in Nkanu West Local Government Area of Enugu State, Nigeria. Dissertation for the award of Fellowship Diploma of the National Postgraduate Medical College of Nigeria in Ophthalmology, 2002.

[12] Onyekwe LO. Visual impairment among school children in Jos, Plateau State, Nigeria. Dissertation for the award of Fellowship Diploma of the National Postgraduate Medical College of Nigeria in Ophthalmology, 1995.

[13] Ashaye AO. Clinical features of primary glaucoma in Ibadan. Nigeria J of Ophthalmol 2003; 11: 70- 75.

[14] Mwanza JC. Primary open-angle glaucoma in Sub-Saharan Africa Nigeria J of Ophthalmol 2006; 14: 22- 26.

[15] Jerald AB, Robert JN, Emily P. Glaucoma, Primary Open Angle. Emedicine on he web. August 16, 2005 [Acessed on emedicine $7^{\text {th }}$ June, 2008].

[16] Hollows FC, Graham PA. Intra-ocular pressure, glaucoma and glaucoma suspects in a defined population. Br J Ophthalmol 1966; 50: 570 .

[17] Jackson C, Bullock J, Pitt M, Keogh J, Glasson W, Hirst L. Screening for glaucoma in a Brisbane general practice-the role of tonometry. Aust N Z J Ophthalmol 1995; 23: 173-8. 
[18] Tielsch JM, Katz J, Sing K, et al. A population-based evaluation of glaucoma screening: The Baltimore Eye Survey. Am J Epidemiol 1991; 134: 1102-1110.
[19] Olurin O. National Postgraduate Medical College of Nigeria. Third Faculty of Ophthalmology lecture. Glaucoma Revisited: $18^{\text {th }}$, August, 2000; 3-8.

[20] Kocur I. What's new at the back of the eye? Community Eye Health J 2006; 19: 1-3.

(C) Ayanniyi et al.; Licensee Bentham Open.

This is an open access article licensed under the terms of the Creative Commons Attribution Non-Commercial License (http://creativecommons.org/licenses/by$\mathrm{nc} / 3.0 /$ /) which permits unrestricted, non-commercial use, distribution and reproduction in any medium, provided the work is properly cited. 